\title{
Alkaline Post-Incubation Improves the Saccharification of Poplar after Hydrogen Peroxide- Acetic Acid Pretreatment
}

\author{
Peiyao Wen \\ Nanjing Forestry University \\ Ying Zhang \\ Northwest A\&F University: Northwest Agriculture and Forestry University \\ Junjun Zhu \\ Nanjing Forestry University \\ Yong Xu \\ Nanjing Forestry University \\ Junhua Zhang ( $\square$ junhuazhang@njfu.edu.cn ) \\ Nanjing Forestry University https://orcid.org/0000-0001-9285-8466
}

\section{Research Article}

Keywords: Poplar, hydrogen peroxide-acetic acid pretreatment, Alkaline incubation, Deacetylation, Enzymatic hydrolysis

Posted Date: May 5th, 2021

DOI: https://doi.org/10.21203/rs.3.rs-474746/v1

License: () (i) This work is licensed under a Creative Commons Attribution 4.0 International License.

Read Full License 


\section{Abstract}

Background: Hydrogen peroxide-acetic acid (HPAA) is widely used in pretreatment of lignocellulose because it has a good capability in selective delignification. However, high concentration (more than $60 \%$ ) of HPAA increases the cost of pretreatment and the risk of explosion. In this work, alkaline post-incubation was employed to decrease the HPAA loading and improve the saccharification of poplar.

Results: Pretreatment with 100\% HPAA removed $91.0 \%$ lignin and retained $89.9 \%$ glucan in poplar. After poplar was pretreated by $100 \%$ HPAA at $60^{\circ} \mathrm{C}$ for $2 \mathrm{~h}$, the glucan conversion in enzymatic hydrolysis by cellulase increased to $90.1 \%$. The total lignin, surface lignin, and acetyl group of HPAA-pretreated poplar were removed by alkaline incubation. More than $92 \%$ acetyl groups of HPAA-pretreated poplar were removed by $1.0 \% \mathrm{NaOH}$. After incubation of $60 \%$ HPAA-pretreated poplar with $1.0 \% \mathrm{NaOH}$, the glucan conversion enhanced to $95.0 \%$. About $40 \%$ HPAA loading in pretreatment was reduced by alkaline incubation without the decrease of glucose yield.

Conclusions: Alkaline post-incubation has strong ability on the deacetylation and delignification of HPAApretreated poplar, exhibiting a strong promotion on the enzymatic hydrolysis yield. This report represented alkaline incubation reduced the HPAA loading, improved pretreatment safety, exhibiting excellent potential application in saccharification of poplar.

\section{Background}

Poplar as a lignocellulosic material is widely used in biomass conversion [1]. Pretreatment technology is a key step for biomass conversion to produce biofuel [2-4]. The suitable pretreatment method of biomass can break the rigid structure of poplar, which is beneficial to the subsequent enzymatic hydrolysis [2-5]. However, poplar has higher lignin content and stronger physical resistance, which limit the enzymatic hydrolysis of poplar [6]. Therefore, it is necessary to remove the lignin of poplar by pretreatment to overcome the recalcitrance in enzymatic hydrolysis.

Recently, hydrogen peroxide-acetic acid (HPAA) is widely used in pretreatment because it has a good capability in selective delignification [7-10]. More than $98.1 \%$ lignin was removed from pine wood by $100 \%$ HPAA at $80^{\circ} \mathrm{C}$ [10]. $100 \%$ HPAA pretreatment can remove $90.3 \%$ lignin of Jerusalem artichoke and improve enzymatic hydrolysis yield to $86.0 \%$ [9]. However, after the acetic acid-pretreated poplar was pretreated with $100 \%$ HPAA at $60^{\circ} \mathrm{C}$, the acetyl group increased from 5.9-8.0\% [11]. The acetyl in glucan and xylan impacts its hydrolysis by cellulase or xylanase due to the steric hindrance of the acetyl groups [12-14]. Pretreatment with $0.1 \%$ sodium hydroxide can increase the glucose yield of HPAA-pretreated poplar from $67.2-74.4 \%$ [11]. However, the effect of sodium hydroxide incubation on the removal of acetyl in poplar has not been investigated. And the effect of sodium hydroxide concentration on surface characterization and digestibility of HPAA-pretreated poplar needs further clarification.

Normally, the high HPAA concentration (more than $60 \%$ ) results in the relatively high costs of HPAA pretreatment [9-11]. Moreover, higher HPAA concentration in HPAA pretreatment faces explosion danger. 
In HPAA system, the formation of peracetic acid is the main reaction and the degradation of hydrogen peroxide is the side reaction $[15,16]$. Pretreatment with higher HPAA concentration can form more peracetic acid, which result in the pretreatment facing explosion danger [15]. Hydrogen peroxide with high concentration with can release lots of oxygen and largely increase the pressure of pretreatment system, which put the HPAA pretreatment at the risk of explosion. Both the formation of peracetic acid and the degradation of hydrogen peroxide require the reduction of HPAA concentration. Hence, the second step pretreatment after HPAA pretreatment is proposed to increase digestibility and reduce the HPAA concentration. Alkaline incubation has been widely used in the second step pretreatment of lignocellulose [17-19]. Therefore, combined HPAA pretreatment with alkali pretreatment has not been reported and the effect of alkaline incubation on reducing HPAA loading and increasing hydrolysis yield was not clear.

Herein, the effects of HPAA concentration on lignin removal and enzymatic hydrolysis of poplar were explored. Then, $0.1 \%$ and $1.0 \%$ sodium hydroxide were used to investigate the effects of alkaline postincubation on the removal of acetyl group in HPAA-pretreated poplar. Effects of acetyl and lignin contents on the enzymatic hydrolysis of poplar after HPAA pretreatment and alkaline incubation were evaluated. The potential of alkaline post-incubation to decrease the cost and improve the safety of HPAA pretreatment were discussed.

\section{Results And Discussion \\ HPAA pretreatment Component analysis}

After poplar was pretreated by $40 \%, 60 \%, 80 \%$ and $100 \%$ HPAA, the lignin contents of poplar decreased from $27.9-26.5 \%, 19.8 \%, 7.7 \%$ and $4.5 \%$, respectively (Table 1). Most glucan (89.9-98.7\%) were retained after HPAA pretreatment. More than $82.0 \%$ lignin in poplar was removed and $92.1 \%$ glucan of poplar was retained after $80 \%$ HPAA pretreatment. This data showed that HPAA pretreatment has strong glucan retention capacity and selectively delignification capability [11]. 
Table 1

Chemical compositions of HPAA-pretreated poplar, expressed as percentage of dry matter.

\begin{tabular}{|c|c|c|c|c|c|c|c|c|}
\hline \multirow{2}{*}{$\begin{array}{l}\text { Pretreatment } \\
\text { label }\end{array}$} & \multirow{2}{*}{$\begin{array}{l}\text { Glucan } \\
(\%)\end{array}$} & \multirow{2}{*}{$\begin{array}{l}\text { Xylan } \\
(\%)\end{array}$} & \multirow{2}{*}{$\begin{array}{l}\text { Lignin } \\
\text { (\%) }\end{array}$} & \multirow{2}{*}{$\begin{array}{l}\text { Acetyl } \\
(\%)\end{array}$} & \multirow{2}{*}{$\begin{array}{l}\text { Solid } \\
\text { recovery (\%) }\end{array}$} & \multicolumn{3}{|c|}{ Removal } \\
\hline & & & & & & $\begin{array}{l}\text { Glucan } \\
\text { (\%) }\end{array}$ & $\begin{array}{l}\text { Xylan } \\
(\%)\end{array}$ & $\begin{array}{l}\text { Lignin } \\
\text { (\%) }\end{array}$ \\
\hline Raw & $\begin{array}{l}43.4 \pm \\
0.0\end{array}$ & $\begin{array}{l}17.4 \pm \\
0.2\end{array}$ & $\begin{array}{l}27.9 \pm \\
0.3\end{array}$ & $\begin{array}{l}3.7 \pm \\
0.2\end{array}$ & - & - & - & - \\
\hline $\mathrm{HPAA}_{40}$ & $\begin{array}{l}47.4 \pm \\
0.1\end{array}$ & $\begin{array}{l}15.7 \pm \\
0.3\end{array}$ & $\begin{array}{l}26.5 \pm \\
0.4\end{array}$ & $\begin{array}{l}5.1 \pm \\
0.3\end{array}$ & 90.2 & 1.3 & 18.7 & 14.3 \\
\hline $\mathrm{HPAA}_{60}$ & $\begin{array}{l}55.0 \pm \\
0.2\end{array}$ & $\begin{array}{l}18.1 \pm \\
0.1\end{array}$ & $\begin{array}{l}19.8 \pm \\
0.2\end{array}$ & $\begin{array}{l}5.8 \pm \\
0.3\end{array}$ & 72.4 & 8.3 & 24.4 & 48.6 \\
\hline $\mathrm{HPAA}_{80}$ & $\begin{array}{l}63.7 \pm \\
0.7\end{array}$ & $\begin{array}{l}20.0 \pm \\
0.3\end{array}$ & $\begin{array}{l}7.7 \pm \\
0.0\end{array}$ & $\begin{array}{l}5.5 \pm \\
0.7\end{array}$ & 62.7 & 7.9 & 27.7 & 82.8 \\
\hline HPAA $_{100}$ & $\begin{array}{l}70.8 \pm \\
0.6\end{array}$ & $\begin{array}{l}19.5 \pm \\
0.2\end{array}$ & $\begin{array}{l}4.5 \pm \\
0.5\end{array}$ & $\begin{array}{l}5.9 \pm \\
0.7\end{array}$ & 55.1 & 10.1 & 38.1 & 91.2 \\
\hline
\end{tabular}

HPAA pretreatment increased the acetyl group of poplar sample from 3.7-5.1\%-5.9\% (Table 1). The increase of acetyl content was consistent with the result in other report [11]. The formation of acetyl group could be attributed to the reason that hydroxyl group of cellulose and xylan can be esterified by acetic acid under the catalysis of sulfuric acid [12-14].

HPAA pretreatment increased the acetyl content of poplar (Table 1). The grafting of extensive acetyl group on the cellulose or hemicellulose hindered the adsorption of cellulases, thereby decreasing the monosaccharides yield of saccharification process $[13,14,19]$. Therefore, it is necessary further remove the acetyl group of HPAA-pretreated poplar.

\section{XPS analysis}

The higher $\mathrm{O} / \mathrm{C}$ ratio reflects lower lignin and extractives contents on the surface of biomass [20]. The $\mathrm{O} / \mathrm{C}$ ration of $\mathrm{HPAA}_{40}$-pretreated poplar was 0.38 , which was close to the 0.39 of non-pretreated poplar (Table 2). When the HPAA concentration was higher than $40 \%$, the $\mathrm{O} / \mathrm{C}$ ratio of poplar increased to $0.40-$ 0.45 . This data showed that pretreatment with $60-100 \%$ HPAA could decrease the lignin or extraction content on the surface of poplar [21]. Meanwhile, the $\mathrm{C} 1$ peak is primarily composed of lignin and extractives [22]. With HPAA concentration increased from $40-100 \%$, the $\mathrm{C} 1$ peak value of the poplar was decreased from $55.1-46.7 \%$, which showed that increasing HPAA loading could remove the lignin from the surface of poplar [20,22]. 
Table 2

XPS analysis of HPAA-pretreated poplar

\begin{tabular}{|l|lllll|}
\hline Pretreatment label & O/C & C1 (\%) & C2 (\%) & C3 (\%) \\
\hline Raw & $0.39 \pm 0.0$ & $56.3 \pm 0.1$ & $31.3 \pm 0.5$ & $12.4 \pm 0.4$ \\
\hline $\mathrm{HPAA}_{40}$ & $0.38 \pm 0.0$ & $55.1 \pm 0.2$ & $33.4 \pm 0.1$ & $11.5 \pm 0.3$ \\
\hline $\mathrm{HPAA}_{60}$ & $0.40 \pm 0.0$ & $52.3 \pm 0.7$ & $34.7 \pm 0.5$ & $13.0 \pm 0.1$ \\
\hline $\mathrm{HPAA}_{80}$ & $0.45 \pm 0.0$ & $46.7 \pm 0.0$ & $37.6 \pm 0.7$ & $15.7 \pm 0.7$ \\
\hline $\mathrm{HPAA}_{100}$ & $0.43 \pm 0.0$ & $47.3 \pm 0.6$ & $37.0 \pm 1.1$ & $15.7 \pm 0.5$ \\
\hline
\end{tabular}

After poplar pretreated with $40-100 \%$ HPAA for $2 \mathrm{~h}$, glucose yields of poplar by a CTec2 loading of 10 FPU/g DM increased from 11.4-16.5\%-90.1\% (Fig. 1A). This result might be attributed to the lignin removal of poplar by HPAA pretreatment $[9,11]$. With HPAA concentration increased from $40-100 \%$, the glucose and xylose yields of poplar samples improved from $16.5 \%$ and $12.0-90.1 \%$ and $84.9 \%$, respectively (Fig. 1). The glucose yield of $\mathrm{HPAA}_{80}$-pretreated poplar was $88.1 \%$, which was slightly lower than those yields of HPAA 100 -pretreated poplar. This data showed that excessive HPAA loading (more than $80 \%$ ) cannot greatly improve the hydrolysis yield of poplar.

\section{Alkaline post-incubation}

\section{Component analysis}

After alkaline post-incubation with $0.1 \%$ sodium hydroxide, $15.6-37.8 \%$ acetyl groups of HPAA-pretreated poplar were removed (Table 3). Meanwhile, 22.1-64.5\% lignin of HPAA-pretreated poplar were removed. The acetyl and lignin removals of $\mathrm{HPAA}_{100}$-pretreated poplar were higher than those of $\mathrm{HPAA}_{60}$ - and $\mathrm{HPAA}_{80}$-pretreated poplar. Those data suggested that the acetyl and lignin of poplar pretreated with higher HPAA concentration might be easier removed by $0.1 \%$ sodium hydroxide. 
Table 3

Chemical compositions of HPAA-SH-pretreated poplar, expressed as percentage of dry matter. The removal of HPAA-SH-pretreated poplar was based on the HPAA-pretreated poplar

\begin{tabular}{|c|c|c|c|c|c|c|c|c|c|}
\hline \multirow{2}{*}{$\begin{array}{l}\text { Pretreatment } \\
\text { label }\end{array}$} & \multirow{2}{*}{$\begin{array}{l}\text { Glucan } \\
(\%)\end{array}$} & \multirow{2}{*}{$\begin{array}{l}\text { Xylan } \\
\text { (\%) }\end{array}$} & \multirow{2}{*}{$\begin{array}{l}\text { Lignin } \\
\text { (\%) }\end{array}$} & \multirow{2}{*}{$\begin{array}{l}\text { Acetyl } \\
\text { (\%) }\end{array}$} & \multirow{2}{*}{$\begin{array}{l}\text { Solid } \\
\text { recovery } \\
(\%)\end{array}$} & \multicolumn{4}{|c|}{ Removal } \\
\hline & & & & & & $\begin{array}{l}\text { Glucan } \\
\text { (\%) }\end{array}$ & $\begin{array}{l}\text { Xylan } \\
\text { (\%) }\end{array}$ & $\begin{array}{l}\text { Lignin } \\
\text { (\%) }\end{array}$ & $\begin{array}{l}\text { Acetyl } \\
\text { (\%) }\end{array}$ \\
\hline $\begin{array}{l}\mathrm{HPAA}_{40^{-}} \\
\mathrm{SH}_{0.1}\end{array}$ & $\begin{array}{l}52.0 \pm \\
0.9\end{array}$ & $\begin{array}{l}17.8 \\
\pm 0.4\end{array}$ & $\begin{array}{l}19.7 \\
\pm 0.1\end{array}$ & $\begin{array}{l}4.8 \pm \\
0.2\end{array}$ & 87.7 & 4.0 & 0.2 & 34.8 & 16.8 \\
\hline $\begin{array}{l}\mathrm{HPAA}_{60^{-}} \\
\mathrm{SH}_{0.1}\end{array}$ & $\begin{array}{l}56.3 \pm \\
0.2\end{array}$ & $\begin{array}{l}18.9 \\
\pm 0.3\end{array}$ & $\begin{array}{l}16.8 \\
\pm 0.1\end{array}$ & $\begin{array}{l}5.3 \pm \\
0.2\end{array}$ & 92.0 & 5.8 & 4.1 & 22.1 & 15.6 \\
\hline $\begin{array}{l}\mathrm{HPAA}_{80^{-}} \\
\mathrm{SH}_{0.1}\end{array}$ & $\begin{array}{l}68.0 \pm \\
0.5\end{array}$ & $\begin{array}{l}20.0 \\
\pm 0.3\end{array}$ & $\begin{array}{l}4.1 \pm \\
0.0\end{array}$ & $\begin{array}{l}5.2 \pm \\
0.1\end{array}$ & 89.5 & 4.5 & 10.5 & 52.5 & 15.6 \\
\hline $\begin{array}{l}\mathrm{HPAA}_{100^{-}} \\
\mathrm{SH}_{0.1}\end{array}$ & $\begin{array}{l}71.9 \pm \\
0.6\end{array}$ & $\begin{array}{l}18.4 \\
\pm 0.4\end{array}$ & $\begin{array}{l}1.9 \pm \\
0.0\end{array}$ & $\begin{array}{l}4.3 \pm \\
0.3\end{array}$ & 85.3 & 13.4 & 19.4 & 64.5 & 37.8 \\
\hline $\begin{array}{l}\mathrm{HPAA}_{40^{-}} \\
\mathrm{SH}_{1.0}\end{array}$ & $\begin{array}{l}56.1 \pm \\
0.1\end{array}$ & $\begin{array}{l}18.4 \\
\pm 0.0\end{array}$ & $\begin{array}{l}18.8 \\
\pm 0.2\end{array}$ & $\begin{array}{l}0.5 \pm \\
0.0\end{array}$ & 79.8 & 5.7 & 6.4 & 43.6 & 92.1 \\
\hline $\begin{array}{l}\mathrm{HPAA}_{60^{-}} \\
\mathrm{SH}_{1.0}\end{array}$ & $\begin{array}{l}68.2 \pm \\
0.4\end{array}$ & $\begin{array}{l}20.1 \\
\pm 0.2\end{array}$ & $\begin{array}{l}6.1 \pm \\
0.0\end{array}$ & $\begin{array}{l}0.5 \pm \\
0.0\end{array}$ & 76.2 & 5.5 & 15.4 & 76.7 & 93.9 \\
\hline $\begin{array}{l}\mathrm{HPAA}_{80^{-}} \\
\mathrm{SH}_{1.0}\end{array}$ & $\begin{array}{l}76.7 \pm \\
2.5\end{array}$ & $\begin{array}{l}20.0 \\
\pm 0.2\end{array}$ & $\begin{array}{l}1.4 \pm \\
0.0\end{array}$ & $\begin{array}{l}0.4 \pm \\
0.0\end{array}$ & 77.5 & 6.7 & 22.4 & 85.4 & 94.7 \\
\hline $\begin{array}{l}\mathrm{HPAA}_{100^{-}} \\
\mathrm{SH}_{1.0}\end{array}$ & $\begin{array}{l}80.5 \pm \\
2.6\end{array}$ & $\begin{array}{l}17.7 \\
\pm 0.8\end{array}$ & $\begin{array}{l}0.2 \pm \\
0.0\end{array}$ & $\begin{array}{l}0.4 \pm \\
0.0\end{array}$ & 75.7 & 14.0 & 31.5 & 96.5 & 95.0 \\
\hline
\end{tabular}

However, when the sodium hydroxide concentration increased to $1.0 \%$, the acetyl of HPAA-SH H.o $_{\text {-pretreated }}$ poplar were greatly decreased to $0.4-0.5 \%$ (Table 3 ). This data showed that $1.0 \%$ sodium hydroxide is very effective at the deacetylation of the HPAA-pretreated poplar. Meanwhile, 43.6-96.5\% lignin of HPAApretreated poplar were removed by $1.0 \%$ sodium hydroxide. These data suggested that $1.0 \%$ sodium hydroxide pretreatment had relatively strong delignification and deacetylation ability on HPAA-pretreated poplar.

\section{XPS analysis}

After alkaline post-incubation with $0.1 \%$ sodium hydroxide, the $\mathrm{O} / \mathrm{C}$ ratio of HPAA pretreated poplar improved to $0.39-0.47$ (Table 4). A high $\mathrm{O} / \mathrm{C}$ suggests higher carbohydrate content is cover on the surface of biomass, while a low $\mathrm{O} / \mathrm{C}$ shows more lignin [23]. This data indicated that alkaline post-incubation can reduce the surface lignin of HPAA-pretreated poplar [21, 24]. This result was consistent with the previous report that sodium hydroxide treatment decreased the surface lignin of Hybrid Pennisetum [24]. When the 
sodium hydroxide concentration was increased to $1.0 \%$, the $\mathrm{O} / \mathrm{C}$ ratios of poplar of HPAA- pretreated poplar were increased to $0.40-0.50$, which were higher than those of HPAA-SH $\mathrm{H}_{0.1}$-pretreated poplar. It implied that post-incubation with $1.0 \%$ sodium hydroxide could remove more surface lignin of HPAApretreated poplar than that with $0.1 \%$ sodium hydroxide. The decrease of surface lignin would be beneficial to the following hydrolysis of HPAA-pretreated poplar as surface lignin limits the accessibility of cellulase to cellulose in poplar [25].

Table 4

XPS analysis of HPAA-SH-pretreated poplar

\begin{tabular}{|lllll|}
\hline Pretreatment label & O/C & C1 (\%) & C2 (\%) & C3 (\%) \\
\hline $\mathrm{HPAA}_{40}-\mathrm{SH}_{0.1}$ & $0.39 \pm 0.0$ & $54.4 \pm 0.3$ & $32.9 \pm 0.6$ & $12.7 \pm 0.3$ \\
\hline $\mathrm{HPAA}_{60}-\mathrm{SH}_{0.1}$ & $0.42 \pm 0.0$ & $49.3 \pm 0.1$ & $36.0 \pm 0.5$ & $14.6 \pm 0.4$ \\
\hline $\mathrm{HPAA}_{80}-\mathrm{SH}_{0.1}$ & $0.47 \pm 0.0$ & $43.8 \pm 0.3$ & $41.5 \pm 0.0$ & $14.7 \pm 0.3$ \\
\hline $\mathrm{HPAA}_{100}-\mathrm{SH}_{0.1}$ & $0.46 \pm 0.0$ & $45.6 \pm 0.0$ & $38.1 \pm 0.3$ & $16.3 \pm 0.3$ \\
\hline $\mathrm{HPAA}_{40}-\mathrm{SH}_{1.0}$ & $0.40 \pm 0.0$ & $53.4 \pm 0.2$ & $34.9 \pm 0.8$ & $11.7 \pm 0.6$ \\
\hline $\mathrm{HPAA}_{60}-\mathrm{SH}_{1.0}$ & $0.44 \pm 0.0$ & $49.4 \pm 0.1$ & $37.5 \pm 0.2$ & $13.1 \pm 0.1$ \\
\hline $\mathrm{HPAA}_{80}-\mathrm{SH}_{1.0}$ & $0.50 \pm 0.0$ & $43.6 \pm 0.1$ & $41.5 \pm 0.1$ & $15.0 \pm 0.0$ \\
\hline $\mathrm{HPAA}_{100}-\mathrm{SH}_{1.0}$ & $0.50 \pm 0.0$ & $40.6 \pm 0.2$ & $43.0 \pm 0.3$ & $16.5 \pm 0.0$ \\
\hline
\end{tabular}

\section{Enzymatic hydrolysis}

After alkaline post-incubation with $0.1 \%$ sodium hydroxide, the glucose yields of $\mathrm{HPAA}_{40^{-}}, \mathrm{HPAA}_{60^{-}}$, and HPAA $_{80}$-pretreated poplar samples increased from $16.5-88.1 \%$ to $19.3-98.9 \%$ (Fig. 2A), respectively. This increase was due to the delignification and deacetylation by alkaline incubation $[12,26]$. Unexpectedly, incubation with $0.1 \% \mathrm{NaOH}$ decreased the glucose yield of $\mathrm{HPAA}_{100}$-pretreated poplar from $90.1-80.3 \%$. Meanwhile, the glucose yield (90.8\%) of $\mathrm{HPAA}_{80} \mathrm{SH}_{1.0}$-pretreated poplar was lower than that of $\mathrm{HPAA}_{80^{-}}$ $\mathrm{SH}_{0.1}$ pretreated poplar (98.9\%). This phenomenon has been confirmed by many other authors, which exhibited further delignification of sample by alkaline incubation cannot increase efficiency of enzymatic hydrolysis anymore $[27,28]$. These results might be due to that higher sodium hydroxide and HPAA concentration removed much amorphous cellulose [11] of poplar because the amorphous cellulose was easier to hydrolysis [29]. Furthermore, excessive removal of lignin during pretreatment results in the aggregation of cellulose, which could negatively affect the surface accessibility $[29,30]$. Hence, the aggregation of cellulose by pretreatment could be a reason that higher HPAA or alkali concentrations reduced the hydrolysis yield of poplar. 
When the sodium hydroxide concentration increased to $1.0 \%$, the glucose yields of $\mathrm{HPAA}_{40^{-}}-\mathrm{SH}_{1.0^{-}}, \mathrm{HPAA}_{60^{-}}$ $\mathrm{SH}_{1.0^{0}}, \mathrm{HPAA}_{80}-\mathrm{SH}_{1.0}$, and $\mathrm{HPAA}_{100}-\mathrm{SH}_{1.0}$-pretreated poplar were $65.1 \%, 95.0 \%, 90.8 \%$, and $91.7 \%$, respectively. The glucose yields of $\mathrm{HPAA}_{60}-\mathrm{SH}_{1.0}$-and $\mathrm{HPAA}_{100}$-pretreated poplar were close (Figs. 1 and 3 ), which showed that alkaline incubation can reduce $40 \%$ HPAA loading in pretreatment without obvious decrease of hydrolysis yield.

Additionally, alkaline post-incubation with $1.0 \%$ sodium hydroxide greatly improved the xylose yield of HPAA-pretreated poplar from $12.0-85.7 \%$ to $77.0-95.2 \%$ (Fig. 2B). These data could be due to alkaline post-incubation removed the acetyl group of hemicellulose in HPAA-pretreated poplar, which reduced the steric hindrance of acetyl group to xylanase and improved the hydrolysis efficiency of xylanase [13].

It was found that linear relationship $\left(R^{2}>0.95\right)$ existed between the glucose and xylose yields in enzymatic hydrolysis of HPAA- and HPAA-SH-pretreated poplar (Fig. 3). This result could be due to the synergistic effect of the cellulase and xylanase in CTec2 affected the enzymatic hydrolysis [31]. Higher xylose yields were got from HPAA-SH ${ }_{1.0}$-pretreated poplar than HPAA- and HPAA-SH H.1 -pretreated poplar when the same amount of glucose was released. This data showed that the xylan in HPAA-SH $1.0^{-}$ pretreated poplar was more easily hydrolyzed.

\section{Relationship between lignin content and hydrolysis yield}

In alkaline incubation process, lignin content and acetyl group are two main factors affecting enzymatic hydrolysis of pretreated materials $[28,32]$. The lignin in pretreated lignocellulose is an important factor affecting enzymatic hydrolysis [32]. In a certain range of lignin content, the materials with lower lignin content are more easily degraded by cellulase [28]. In this work, the relationships between lignin contents and the glucose yields of HPAA- and HPAA-SH-pretreated poplar were analyzed. The HPAA-SH-pretreated poplar showed lower linear correlation $\left(R^{2}=0.72-0.82\right)$ than that of HPAA-pretreated poplar $(0.9)$. This result might be due to alkaline incubation removed excessive lignin of poplar and excessive delignification of poplar, which could not increase efficiency of enzymatic hydrolysis anymore [28].

A linear relationship $\left(R^{2}>0.94\right)$ existed between lignin content and the xylose yields in the hydrolysis of

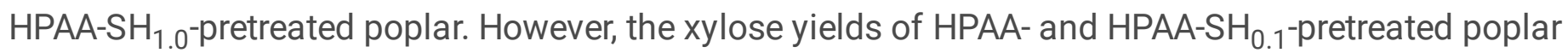
showed lower linear correlation with lignin contents. These data could be due to the more acetyl in the HPAA- and HPAA-SH ${ }_{0.1}$-pretreated poplar (Tables 1 and 3), which could affect the hydrolysis of poplar xylan [12].

\section{Relationship between acetyl content and hydrolysis yield}

After alkaline incubation with different concentrations of sodium hydroxide, the HPAA-SH-pretreated poplar samples contained different acetyl contents (Table 3). When the HPAA concentrations in pretreatment were $40 \%$ or $60 \%$, a linear relationship $\left(R^{2}>0.99\right)$ between acetyl content and monosaccharides (glucose and xylose) yields existed. This data indicated that acetyl content played a very important role in the hydrolysis of $40 \%$ and $60 \%$ HPAA pretreated poplar [32]. However, it was not 
found the linear relation between acetyl content and monosaccharides yields in $80 \%$ and $100 \%$ HPAApretreated poplar, which indicated that besides acetyl group, there some other factors (such as cellulase and xylanase activities in hydrolysate, inhibitor in hydrolysate, amorphous cellulose content in samples) might affect the enzymatic hydrolysis of $80 \%$ or $100 \%$ HPAA-pretreated poplar [32, 33].

\section{Mass balance}

Figure 4 presented the mass balance of poplar after HPAA pretreatment and subsequent enzymatic hydrolysis using CTec2. After pretreatment with 100\% HPAA, $390.5 \mathrm{~g}$ glucose and $103.8 \mathrm{~g}$ xylose were got from $1000 \mathrm{~g}$ raw poplar by enzymatic hydrolysis. Interestingly, $\mathrm{HPAA}_{60}-\mathrm{SH}_{1.0}$ and $\mathrm{HPAA}_{80}-\mathrm{SH}_{0.1}$ pretreatments processes gave $514.6 \mathrm{~g}$ and $536.1 \mathrm{~g}$ monosaccharides (glucose and xylose) from $1000 \mathrm{~g}$ raw poplar, which were higher than that obtained from $\mathrm{HPAA}_{100}$ pretreatment $(494.3 \mathrm{~g})$ without alkaline post-incubation. These results showed that alkaline incubation not only reduced the HPAA loading in the pretreatment but also increased monosaccharides yields from poplar. In previous report, after poplar pretreated with $80 \%$ HPAA, only $190.0 \mathrm{~g}$ and $86.0 \mathrm{~g}$ were obtained from $1000 \mathrm{~g}$ raw poplar by enzymatic hydrolysis [34]. Compared with the previous report [34], the higher monosaccharides yields obtained in this work improved the economic benefit and the relatively lower HPAA concentration (60\%) improved the safety of pretreatment.

Normally, the pretreatment temperature of poplar is higher than $150{ }^{\circ} \mathrm{C}$ [35-39]. Herein, the temperatures of HPAA pretreatment and alkaline post-incubation were $60^{\circ} \mathrm{C}$ and $50^{\circ} \mathrm{C}$, respectively, which was a relatively mild pretreatment. Moreover, some reports showed relatively low glucose yields (less than $65.0 \%$ ) from pretreated poplar and the cellulase loading were higher than $15 \mathrm{FPU} / \mathrm{g} \mathrm{DM} \mathrm{[40-42].}$ Furthermore, the enzymatic hydrolysis of HPAA-pretreated lignocelluloses needs extra cellulase or surfactant to improve hydrolysis yield $[11,43,44]$. Herein, more than $95.0 \%$ glucose yields were got from poplar and only CTec2 (10 FPU/g DM) was used as cellulase in the enzymatic hydrolysis without extra cellulase or surfactant. Therefore, the HPAA-SH process had a great potential to decrease the cost of monosaccharides production from poplar. To reduce the cost of the HPAA-SH pretreatment, pressure shift distillation can be employed to separate acetic acid and the peracetic acid formed in HPAA solution [45, 46]. Sodium hydroxide solution in alkaline post-incubation can be reused in next process. Furthermore, sodium hydroxide solution also can be diluted and neutralized as a buffer used in enzymatic hydrolysis, which can eliminate washing process of poplar [18]. The process of HPAA and alkaline post-incubation reduced HPAA loading and provided a preferable feature for the production of sugars from poplar with relatively mild conditions.

\section{Conclusions}

HPAA pretreatment removed $14.3-91.2 \%$ lignin of poplar and increased the acetyl content to $5.1-5.9 \%$. More than $93.0 \%$ acetyl and $76.0 \%$ lignin contents of HPAA $_{60}$-pretreated poplar was removed by $1.0 \%$ sodium hydroxide. Alkaline incubation reduced 40\% HPAA loading in pretreatment and increased the glucose yield of $\mathrm{HPAA}_{60}$-pretreated poplar to $95.0 \%$. The results in this work showed that alkaline post- 
incubation has strong ability on the deacetylation and delignification of HPAA-pretreated poplar, exhibiting a strong promotion on the enzymatic hydrolysis yield. This report provided a scientific guidance for production of monosaccharides from poplar by HPAA pretreatment with less HPAA loading and low temperature.

\section{Materials And Methods}

\section{Materials}

The poplar, cellulase (Cellic CTec2), acetic acid, and sodium hydroxide used in this work were consistent with the samples in previous reports $[11,19]$.

\section{HPAA pretreatment}

The HPAA solution and pretreatment method were consistent with our previous research [11]. HPAA pretreatments were investigated at $60^{\circ} \mathrm{C}$ with $40-100 \%(\mathrm{v} / \mathrm{v})$. The pretreatment with $40 \%, 60 \%, 80 \%$, and $100 \%$ HPAA were labeled as $\mathrm{HPAA}_{40}, \mathrm{HPAA}_{60}, \mathrm{HPAA}_{80}$, and $\mathrm{HPAA}_{100}$, respectively.

\section{Alkaline post-incubation}

HPAA-pretreated samples were employed for the subsequent alkaline post-incubation. The alkaline postincubation was performed at $50^{\circ} \mathrm{C}$ for $1 \mathrm{~h}$ with a solid to liquid ratio of $1: 10(\mathrm{w} / \mathrm{v})$ by $0.1 \%$ and $1.0 \%$ sodium hydroxide, respectively, which were labeled as $\mathrm{HPAA}^{-\mathrm{SH}_{0.1}}$ and HPAA-SH${ }_{1.0}$.

\section{Enzymatic hydrolysis}

The enzymatic hydrolysis of poplar samples was consistent with the previous reported method [21].

\section{Analytical methods}

Monosaccharides were analyzed by the method as described previously [21]. The contents of glucan, xylan lignin and acetyl of poplar were determined by the National Renewable Energy Laboratory analytical procedure [47]. XPS analysis was consistent with the method previously reported [48].

\section{Calculations}

The solid recovery and content removal of samples were determined by the reported formulas [11].

\section{Abbreviations}

HPAA: hydrogen peroxide-acetic acid; SH: sodium hydroxide; DM: dry mass; XPS: X-ray photoelectron spectroscopy; FPU: filter paper unit.

\section{Declarations}


PW designed the project, carried out the experiments, analyzed the data, and drafted the manuscript. YZ conducted the experiment of enzymatic hydrolysis. YX and JZ reviewed it. JZ designed and coordinated the overall study and finalized the paper. All authors read and approved the final manuscript.

\section{Author details}

a Jiangsu Co-Innovation Center of Efficient Processing and Utilization of Forest Resources, College of Chemical Engineering, Nanjing Forestry University, Nanjing 210037, China

${ }^{b}$ Key Laboratory of Forestry Genetics \& Biotechnology (Nanjing Forestry University), Ministry of Education, Nanjing 210037, China

${ }^{c}$ College of Forestry, Northwest A\&F University, Yangling 712100, Shaanxi, China

\section{Acknowledgments}

Not applicable.

\section{Competing interests}

The authors declare that they have no competing interests.

\section{Availability of supporting data}

All relevant data have been included in this published article and its Additional file 1.

\section{Consent for publication}

All the authors approved the manuscript.

\section{Ethics approval and consent to participate}

Not applicable.

\section{Funding}

This work was supported by the National Key R\&D Program of China (No. 2017YFD0601001), the National Natural Science Foundation of China (No. 31670598) and the Starting Research Fund from the Nanjing Forestry University (No. 163030103).

\section{References}

1. Devappa RK, Rakshit SK, Dekker RF. Forest biorefinery: potential of poplar phytochemicals as valueadded co-products. Biotechnol Adv. 2015;33(6):681-716.

https://doi.org/10.1016/j.biotechadv.2015.02.012. 
2. Sannigrahi P, Ragauskas AJ, Tuskan GA. Poplar as a feedstock for biofuels: a review of compositional characteristics. Biofuel Bioprod Bior. 2010;4(2):209-26. https://doi.org/10.1002/bbb.206.

3. Huang C, Zhan Y, Du X, Yang Z, Yu L, Meng X, et al. Modified alkaline peroxide pretreatment: An efficient path forward for bioethanol production from bamboo. Energy Convers Manage. 2020;224:113365. https://doi.org/10.1016/j.enconman.2020.113365.

4. Jiang L, Wu Y, Wang X, Zheng A, Zhao Z, Li H, et al. Crude glycerol pretreatment for selective saccharification of lignocellulose via fast pyrolysis and enzyme hydrolysis. Energy Convers Manage. 2019;199:111894. https://doi.org/10.1016/j.enconman.2019.111894.

5. Xu F, Zhang X, Zhou X, Ji Z, Ma J, Ma J. An investigation of dissolution mechanism of major components in cell walls of agricultural and forest biomass. Journal of Forestry Engineering. 2016;1(04):1-9. https://doi.org/10.13360/j.issn.2096-1359.2016.04.001.

6. Demartini JD, Pattathil S, Miller JS, Li H, Hahn MG, Wyman CE. Investigating plant cell wall components that affect biomass recalcitrance in poplar and switchgrass. Energy Environ Sci. 2013;6(3):898-909. https://doi.org/10.1039/C3EE23801F.

7. Basar IA, Perendeci NA. Optimization of zero-waste hydrogen peroxide - Acetic acid pretreatment for sequential ethanol and methane production. Energ. 2021;225:120324. https://doi.org/10.1016/j.energy.2021.120324.

8. Mota TR, Oliveira DM, Morais GR, Marchiosi R, Buckeridge MS, Ferrarese O, et al. Hydrogen peroxideacetic acid pretreatment increases the saccharification and enzyme adsorption on lignocellulose. Ind Crop Prod. 2019;140:111657. https://doi.org/10.1016/j.indcrop.2019.111657.

9. Song Y, Wi SG, Kim HM, Bae H-J. Cellulosic bioethanol production from Jerusalem artichoke (Helianthus tuberosus L.) using hydrogen peroxideacetic acid (HPAC) pretreatment. Bioresour Technol. 2016;214:30-6. https://doi.org/10.1016/j.biortech.2016.04.065.

10. Wi S, Cho E, Lee D, Lee S, Lee Y, Bae H. Lignocellulose conversion for biofuel: a new pretreatment greatly improves downstream biocatalytic hydrolysis of various lignocellulosic materials. Biotechnol Biofuels. 2015;8:228. https://doi.org/10.1186/s13068-015-0419-4.

11. Wen P, Zhang T, Wang J, Lian Z, Zhang J. Production of xylooligosaccharides and monosaccharides from poplar by a two-step acetic acid and peroxide/acetic acid pretreatment. Biotechnol Biofuels. 2019;12:87. https://doi.org/10.1186/s13068-019-1423-x.

12. Chen X, Shekiro J, Franden M, Wang W, Zhang M, Kuhn E, et al. The impacts of deacetylation prior to dilute acid pretreatment on the bioethanol process. Biotechnol Biofuels. 2012;5:8. https://doi.org/10.1186/1754-6834-5-8.

13. Pawar M, Derba Maceluch M, Chong M, Gandla M, Bashar S, Sparrman T, Ahvenainen P, et al. 2017. In muro deacetylation of xylan affects lignin properties and improves saccharification of aspen wood. Biotechnol Biofuels. 2017; 10: 98. https://doi.org/10.1186/s13068-017-0782-4.

14. Pan X. Effect of acetyl groups on enzymatic hydrolysis of cellulosic substrates. Holzforschung. 2006;60(4):398-401. https://doi.org/10.1515/HF.2006.062. 
15. Ma R, Guo M, Lin K, Hebert V, Zhang J, Wolcott M, et al. Peracetic acid depolymerization of biorefinery lignin for production of selective monomeric phenolic compounds. Chem Eur J. 2016;22(31):1088491. https://doi.org/10.1002/chem.201600546.

16. Zhao X, Zhang T, Zhou Y, Liu D. Preparation of peracetic acid from hydrogen peroxide Part I: Kinetics for peracetic acid synthesis and hydrolysis. J Mol Catal A: Chem. 2007;271:246-52. https://doi.org/10.1016/j.molcata.2007.03.012.

17. Qin Y, Wang R, Zhang J. Structure and enzymatic hydrolysis of corn stover with dilute acid pretreatment in $Y$-valerolactone/water system. Journal of Forestry Engineering. 2019;4(01):101-7. https://doi.org/10.13360/j.issn.2096-1359.2019.01.015.

18. Shuai L, Questell-Santiago YM, Luterbacher JS. A mild biomass pretreatment using Y-valerolactone for concentrated sugar production. Green Chem. 2016;18:937-43. https://doi.org/10.1039/c5gc02489g.

19. Wen $P, X u$ Y, Zhang J. Alkaline incubation improves the saccharification of poplar after sodium chlorite pretreatment with ultra-low cellulase loading. Renew Energ. 2021;170:517-24. https://doi.org/10.1016/j.renene.2021.01.142.

20. Johansson L, Campbell J, Hänninen T, Ganne-Chèdeville $C$, Vuorinen T, Hughes $M$, et al. XPS and the medium-dependent surface adaptation of cellulose in wood. Surf Interface Anal. 2012;44:899-903. https://doi.org/10.1002/sia.4839.

21. Wen P, Zhang T, Xu Y, Zhang J. Co-production of xylooligosaccharides and monosaccharides from poplar by a two-step acetic acid and sodium chlorite pretreatment. Ind Crop Prod. 2020;152:112500. https://doi.org/10.1016/j.indcrop.2020.112500.

22. Ma X, Yang X, Zheng X, Chen L, Huang L, Cao S, et al. Toward a further understanding of hydrothermally pretreated holocellulose and isolated pseudo lignin. Cellulose. 2015;22(3):1687-96. https://doi.org/10.1007/s10570-015-0607-1.

23. Kumar R, Mago G, Balan V, Wyman CE. Physical and chemical characterizations of corn stover and poplar solids resulting from leading pretreatment technologies. Bioresour Technol. 2009;100(17):3948-3462. https://doi.org/10.1016/j.biortech.2009.01.075.

24. Yang M, Wang J, Hou X, Wu J, Fan X, Jiang F, et al. Exploring surface characterization and electrostatic property of Hybrid Pennisetum during alkaline sulfite pretreatment for enhanced enzymatic hydrolysability. Bioresour Technol. 2017;244(1):1166. https://doi.org/10.1016/j.biortech.2017.08.046.

25. Nitsos C, Lazaridis P, Mach-Aigner A, Mati SK, Triantafyllidis K. Enhancing lignocellulosic biomass hydrolysis by hydrothermal pretreatment, extraction of surface lignin, wet milling and production of cellulolytic enzymes. ChemSusChem. 2019;12:1179-95. https://doi.org/10.1002/cssc.201802597.

26. Schneider L, Dong Y, Haverinen J, Jaakkola M, Lassi U. Efficiency of acetic acid and formic acid as a catalyst in catalytical and mechanocatalytical pretreatment of barley straw. Biomass Bioenerg. 2016;91:134-42. https://doi.org/10.1016/j.biombioe.2016.05.015. 
27. Ishizawa Cl, Jeoh T, Adney WS. Himmel ME, Johnson DK, Davis MF. Can delignification decrease cellulose digestibility in acid pretreated corn stover? Cellulose. 2009;16:677-86. https://doi.org/10.1007/s10570-009-9313-1.

28. Yan Z, Li J, Li S, Cui T, Jiang Y, Cong G, et al. Impact of lignin content on the sweet sorghum bagasse enzymatic hydrolysis. Energy Procedia. 2014;61:1957-60. https://doi.org/10.1016/j.egypro.2014.12.251.

29. Jeoh T, Ishizawa C, Davis M, Himmel M, Johnson D. Cellulase digestibility of pretreated biomass is limited by cellulose accessibility. Biotechnol Bioeng. 2007;98:112-22. https://doi.org/10.1002/bit.21408.

30. Kafle K, Shin H, Lee C, Park S, Kim S. Progressive structural changes of Avicel, bleached softwood, and bacterial cellulose during enzymatic hydrolysis. Sci rep. 2015;5:1-10. https://doi.org/10.1038/srep15102.

31. Zhang J, Viikari L. Impact of xylan on synergistic effects of xylanases and cellulases in enzymatic hydrolysis of lignocelluloses. Appl Biochem Biotechnol. 2014;174:1393-402. https://doi.org/10.1007/s12010-014-1140-7.

32. Chang V, Holtzapple M. Fundamental factors affecting biomass enzymatic reactivity. Appl Biochem Biotechnol 2000, 84-6, 5-37. https://doi.org/10.1007/978-1-4612-1392-5_1.

33. Xin D, Sun Z, Viikari, Zhang J. 2015. Role of hemicellulases in production of fermentable sugars from corn stover. Ind Crop Prod. 2015; 74: 209-217. https://doi.org/10.1016/j.indcrop.2015.05.017.

34. Ying W, Xu Y, Zhang J. Effect of sulfuric acid on production of xylooligosaccharides and monosaccharides from hydrogen peroxide-acetic acid-pretreated poplar. Bioresour Technol. 2021;321:124472. https://doi.org/10.1016/j.biortech.2020.124472.

35. Bhagia S, Kumar R, Wyman CE. Effects of dilute acid and flowthrough pretreatments. and BSA supplementation on enzymatic deconstruction of poplar by cellulase and xylanase. Carbohydr Polym. 2017;157:1940-8. https://doi.org/10.1016/j.carbpol.2016.11.085.

36. Jiang $\mathrm{H}, \mathrm{Han} \mathrm{B}, \mathrm{Ge} J$. Enhancement in the enzymatic digestibility of hybrid poplar with poor residual hemicelluloses after $\mathrm{Na}_{2} \mathrm{SO}_{3}$ pretreatment. Bioresour Technol. 2015;180:338-44. https://doi.org/10.1016/j.biortech.2014.12.103.

37. Panagiotopoulos IA, Chandra RP, Saddler JN. A two-stage pretreatment approach to maximise sugar yield and enhance reactive lignin recovery from poplar wood chips. Bioresour Technol. 2013;130(1):570-7. https://doi.org/10.1016/j.biortech.2012.12.093.

38. Tian D, Chandra RP, Lee JS, Lu C, Saddler JN. A comparison of various lignin-extraction methods to enhance the accessibility and ease of enzymatic hydrolysis of the cellulosic component of steampretreated poplar. Biotechnol Biofuels. 2017;10:157. https://doi.org/10.1186/s13068-017-0846-5.

39. Zhang L, You T, Zhang L, Yang H, Xu F. Enhanced fermentability of poplar by combination of alkaline peroxide pretreatment and semi-simultaneous saccharification and fermentation. Bioresour Technol. 2014;164:292-8. https://doi.org/10.1016/j.biortech.2014.04.075. 
40. Huang K, Luo J, Cao R, Su Y, Xu Y. Enhanced xylooligosaccharides yields and enzymatic hydrolyzability of cellulose using acetic acid catalysis of poplar sawdust. J Wood Chem Technol. 2018;38(5):371-84. https://doi.org/10.1080/02773813.2018.1500608.

41. Negro MJ, Manzanares P, Ballesteros I, Oliva JM, Cabañas A, Ballesteros M. Hydrothermal pretreatment conditions to enhance ethanol production from poplar biomass. Appl Biochem Biotechnol. 2003;105(1-3):87-100. https://doi.org/10.1385/ABAB:105:1-3:87.

42. Sun Q, Foston M, Meng X, Sawada D, Pingali S, O'Neill H, et al. Effect of lignin content on changes occurring in poplar cellulose ultrastructure during dilute acid pretreatment. Biotechnol Biofuels. 2014;7:150. https://doi.org/10.1186/s13068-014-0150-6.

43. Lee HR, Kazlauskas RJ, Park TH. One-step pretreatment of yellow poplar biomass using peracetic acid to enhance enzymatic digestibility. Sci Rep. 2017;7(1):12216. https://doi.org/10.1038/s41598017-12542-w.

44. Mukasekuru M, Hu J, Zhao X, Sun F, Pascal K, Ren H, et al. Enhanced high-solids fed-batch enzymatic hydrolysis of sugar cane bagasse with accessory enzymes and additives at low cellulase loading. ACS Sustainable Chem Eng. 2018;6:12787-96. https://doi.org/10.1021/acssuschemeng.8b01972.

45. Abdulrahman A, Walsum GP, Um BH. Acetic acid removal from pre-pulping wood extract with recovery and recycling of extraction solvents. Appl Biochem Biotechnol. 2019;187(1):378-95. https://doi.org/10.1007/s12010-018-2826-z.

46. Zhao X, Wu R, Liu D. Production of pulp, ethanol and lignin from sugarcane bagasse by alkaliperacetic acid delignification. Biomass Bioenerg. 2011;35:2874-82. https://doi.org/10.1016/j.biombioe.2011.03.033.

47. Sluiter A, Hanmes B, Ruiz R, Scarlata C, Sluiter J, Templeton D, et al. Determination of Structural Carbohydrates and Lignin in Biomass. Golden: Laboratory Analytical Procedure of National Renewable Energy Laboratory (NREL); 2012.

48. Fougere D, Nanda S, Clarke K, Kozinski J, Li K. Effect of acidic pretreatment on the chemistry and distribution of lignin in aspen wood and wheat straw substrates. Biomass Bioenerg. 2016;91:56-68. https://doi.org/10.1016/j.biombioe.2016.03.027.

\section{Figures}




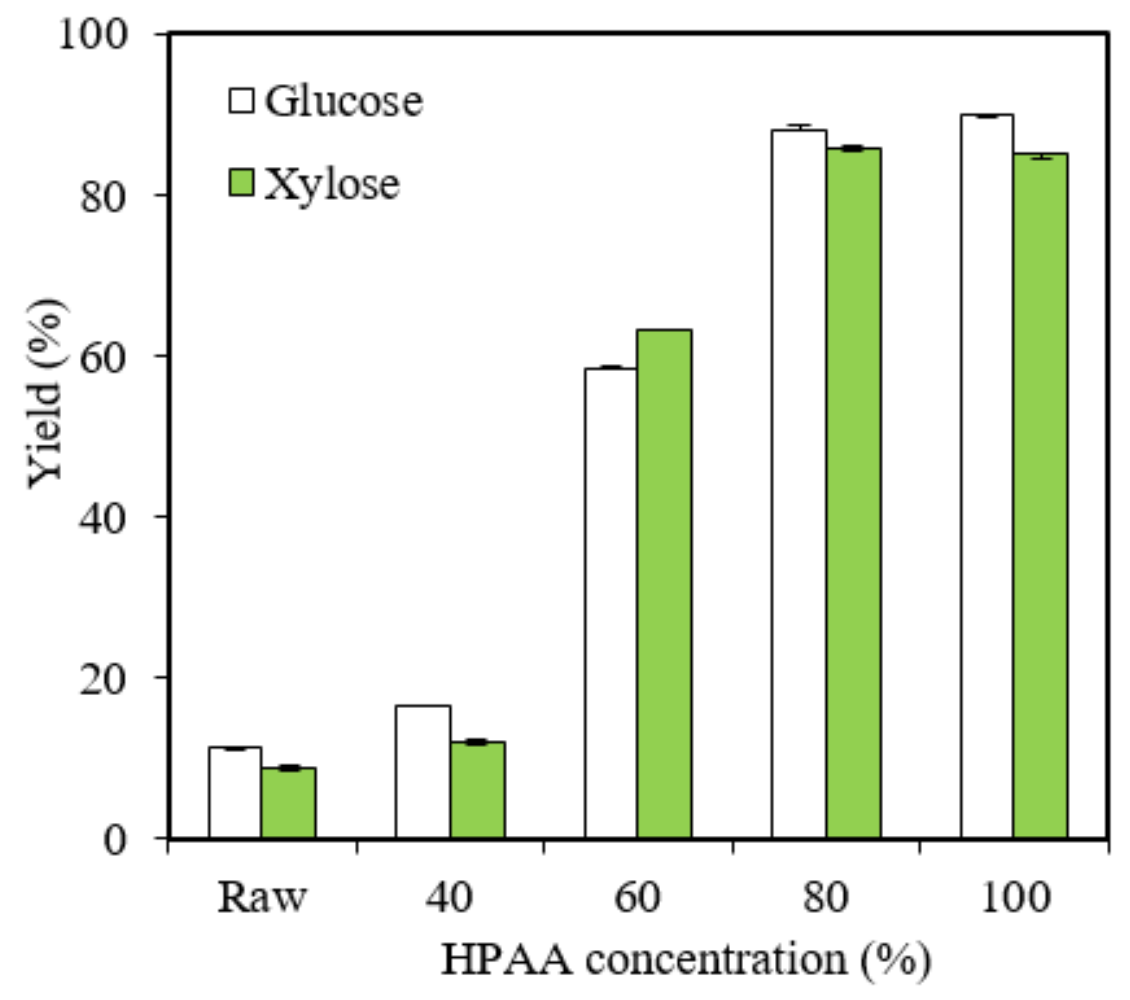

Figure 1

The monosaccharides yields of $40 \%-100 \%$ HPAA-pretreated poplar by CTec2 (10 FPU/g DM) at $50{ }^{\circ} \mathrm{C}$ and $\mathrm{pH} 5.0$ for $72 \mathrm{~h}$.
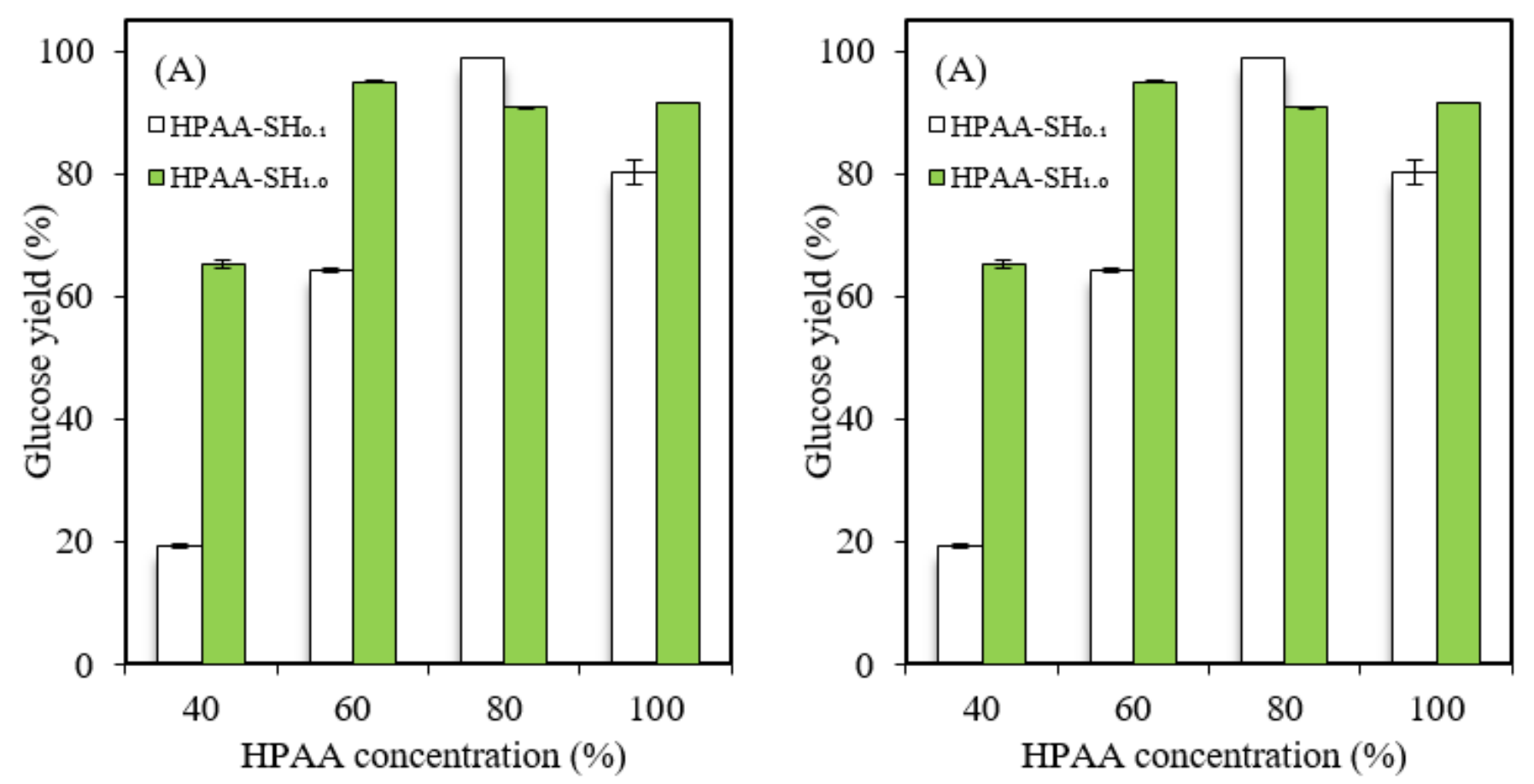

Figure 2 
Effects of alkaline post-incubation on the glucose (A) and xylose (B) yields of $40 \%-100 \%$ HPAA-pretreated poplar by CTec2 (10 FPU/g DM) at $50{ }^{\circ} \mathrm{C}$ and $\mathrm{pH} 5.0$ for $72 \mathrm{~h}$.

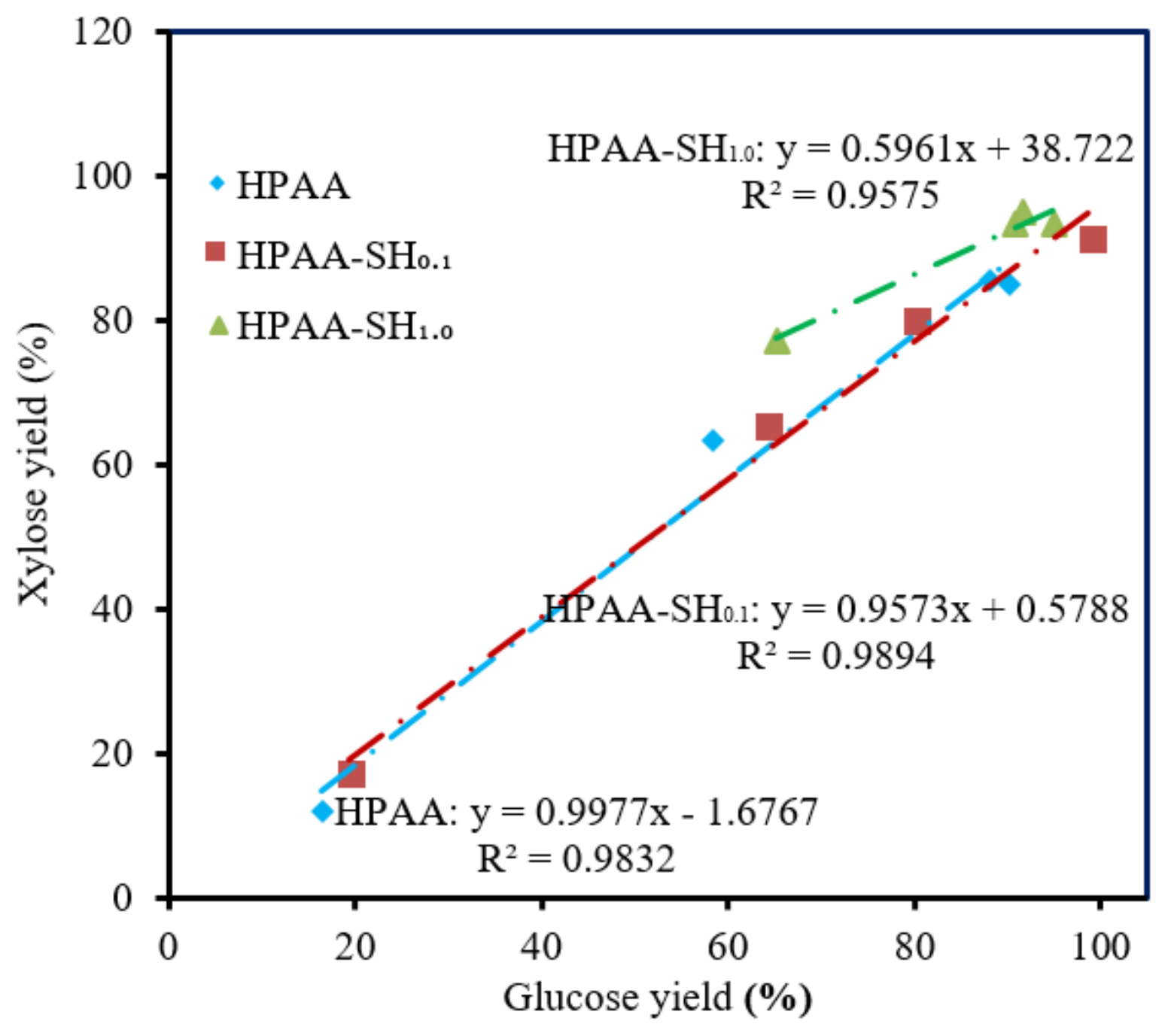

Figure 3

Relationship between xylose and glucose yields in the hydrolysis of 2\% HPAA- and HPAA-SH-pretreated poplar. 


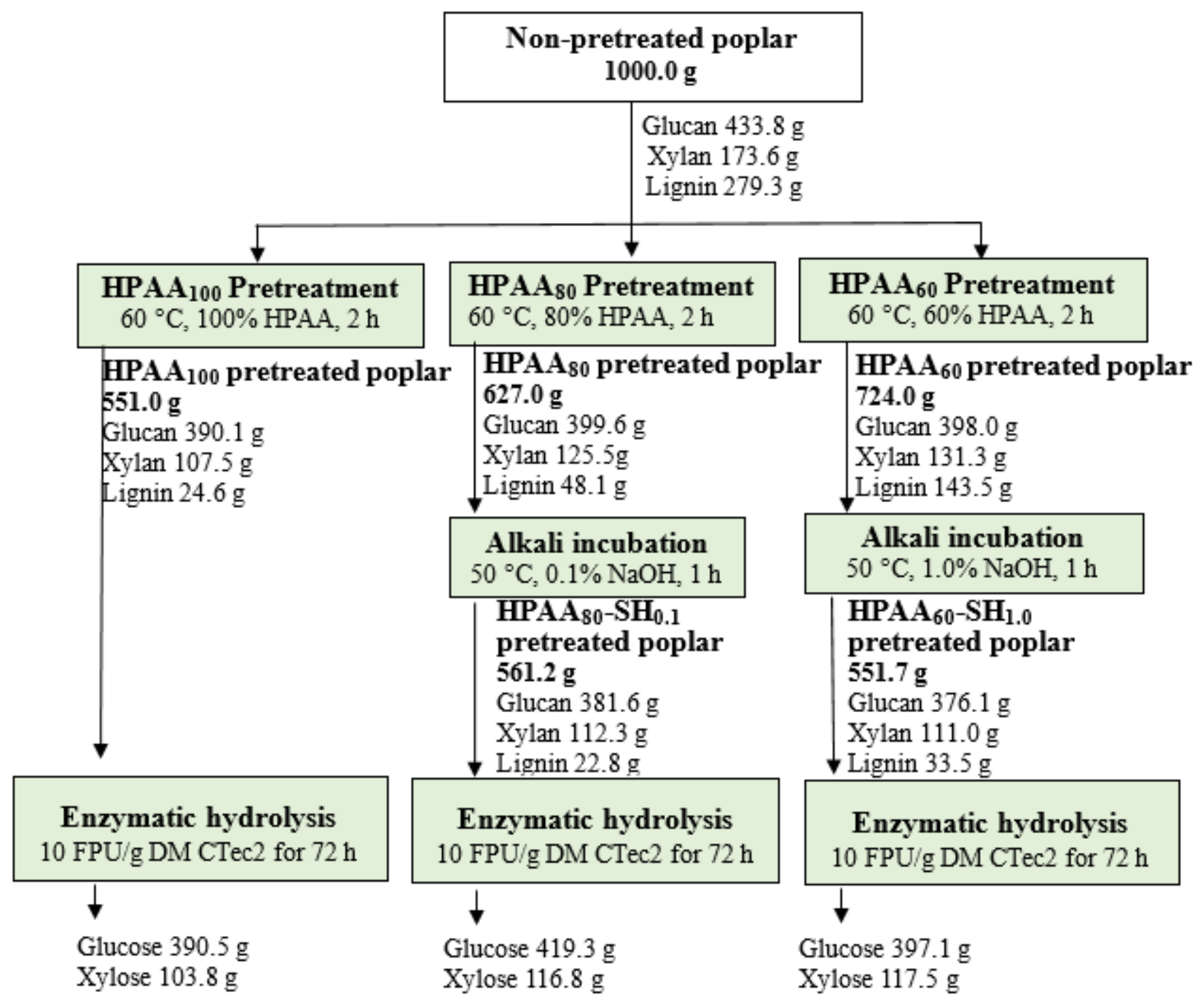

Figure 4

Mass balances for production of monosaccharides from poplar after HPAA80-SH0.1 and HPAA60-SH1.0 pretreatments.

\section{Supplementary Files}

This is a list of supplementary files associated with this preprint. Click to download.

- supplementarymaterials.docx 